\title{
En la frontera del decir: los epígrafes en la narrativa de Sandra Cisneros
}

\author{
In the border of saying: the epigraphs in \\ Sandra Cisneros's narrative
}

\begin{abstract}
María Laura Spoturno
Universidad Nacional de La Plata/ Consejo Nacional de Investigaciones Científicas y Técnicas. Buenos Aires, Argentina. Correo electrónico: lauraspoturno@fahce.unlp.edu.ar
\end{abstract}

En este trabajo nos proponemos indagar acerca de la construcción y del funcionamiento enunciativo-discursivo de los epígrafes en la narrativa de la escritora chicana Sandra Cisneros, que pone de manifiesto un encuentro constitutivo en el que el español y el inglés interactúan de manera particular. La escritora se vale de los intersticios que se producen en el contacto entre lenguas y culturas y allí, en la fisura, construye un nuevo espacio discursivo, que constituye un nuevo decir y que distingue su voz literaria. Nuestra hipótesis es que los epígrafes, pequeños (para)textos en cuyo interior aparece el español a través de un uso efectivo o de distintas alusiones, se erigen en este discurso como formas de la heterogeneidad interlingüe en tanto participan de distintos procesos de negociación y traducción lingüístico-culturales, delineando así una imagen discursiva o ethos. de lectura.

Palabras clave: epígrafes, espacios discursivos, heterogeneidad interlingüe, ethos, gestos

This article aims at exploring the enunciative-discursive construction and function of epigraphs in Sandra Cisneros's narrative work. This Chicana writer's fiction evidences a particular constitutive encounter between English and Spanish. Cisneros resorts to the gaps which result as of this linguistic and cultural contact, producing a new discursive space in the gaps, which amounts to a new way of saying, making her literary voice distinct to the reader. According to our hypothesis, epigraphs are small (para) texts which account for a direct or alluded presence of Spanish and emerge as sites of interlingual heterogeneity as they take part of different processes of linguistic-cultural negotiation and translation, which configure both a certain discursive image or ethos of the locutor responsible for the global enunciation.

Key words: epigraphs, discursive spaces, interlingual heterogeneity, ethos, reading gestures. 


\section{INTRODUCCIÓN}

Este trabajo tiene como objetivo central explorar la construcción fronteriza y el funcionamiento enunciativo-discursivo de los epígrafes en la obra narrativa de la escritora chicana Sandra Cisneros ( $n$. 1954). Su narrativa, que se desarrolla fundamentalmente en inglés, pone de manifiesto un encuentro constitutivo en el que el español y el inglés interactúan de manera particular. Con gran maestría, la escritora se vale de los intersticios que se producen en el contacto entre lenguas y culturas y allí, en la fisura, construye un nuevo espacio discursivo, que instaura un nuevo decir y distingue su voz literaria. Cisneros emplea distintas estrategias para evocar y expresar las particularidades de ese contacto, tanto desde el punto de vista argumental y de la construcción de los personajes y temáticas como desde la puesta en escena de un modo de decir que busca su propio espacio enunciativo en el vínculo con el otro, evocado una y otra vez en el uso efectivo o en la alusión a distintas lenguas en el trabajo de la escritura y reelaborado necesariamente en los procesos de lectura y de relectura ${ }^{1}$. Se trata de un otro marcado, que no se asocia al inglés, sino a otra lengua, cultura y, más específicamente, a otra discursividad. La escritora instala la presencia de un otro en un sitio en el que su marca no siempre es esperable, creando así efectos estéticos singulares. Es relevante agregar que el aprovechamiento de las fisuras presenta una particularidad en su caso. Notablemente, en la exploración y creación simultánea de las fisuras, se vale de elementos discursivos y paratextuales que se conciben, por lo general, como fijos o estereotipados, pero que funcionan aquí de manera polisémica.

En este sentido, los epígrafes de la narrativa de Cisneros se revelan como un punto de interés central. Según sostendremos, los epígrafes, pequeños (para)textos en cuyo interior aparece el español a través de un uso efectivo o de distintas alusiones ${ }^{2}$, constituyen sitios de la heterogeneidad interlingüe (Spoturno 2010) en tanto participan de distintos procesos de negociación y traducción lingüístico-culturales, delineando así una imagen discursiva o ethos (Ducrot [1984] 1986, Maingueneau [1986] 1993, 1999, Amossy 1999) del responsable de la enunciación y un gesto de lectura singular que se plasma en distintas instrucciones de lectura y relectura (García Negroni 2000, Zoppi Fontana 2007). Inscripta en el plano del dialogismo interdiscursivo (Bajtín [1952-3] 1982) y de la heterogeneidad enunciativa (Authier 1984), hemos definido la heterogeneidad interlingüe como un fenómeno discursivo que se manifiesta a través de las marcas y formas que surgen en el discurso a partir de los procesos de negociación y traducción lingüístico-culturales que, en la escritura de Cisneros, se materializan en el encuentro del inglés y del español principalmente. Así, en la puesta en escena de estos sitios de la heterogeneidad interlingüe se definen, por un lado, una imagen discursiva o ethos del responsable de la enunciación global de los relatos (Ducrot [1984] 1986,

1 En este trabajo seguimos los postulados de García Negroni (2000) para caracterizar los procesos de lectura y de relectura que se gestan en el interior de la narrativa de Cisneros. Nos permitimos aclarar que en su trabajo esta investigadora no examina textos literarios en los que aparezcan dos o más lenguas.

2 Distintas investigaciones han abordado el estudio del español en la narrativa chicana escrita en inglés. Para ampliar este tema podrá consultarse Lipski (1982), Cintrón y Mendieta-Lombardo (1995), Rudin (1996), Soler-Espiauba (2001), Cantero y Stewart (2003), Ledwith (2008), entre otros. 
Maingueneau [1986] 1993, 1999; Amossy 1999) y, por el otro, un gesto de lectura particular, que resulta crucial para completar el sentido de los textos.

En relación con ello, entendemos que la misión de los epígrafes es contribuir a ubicar el texto principal en el ámbito de la discursividad latina ${ }^{3}$ a la que se asocian estos elementos paratextuales. Así, por medio de esta operación surge en el discurso una imagen discursiva o ethos determinado del responsable de la enunciación y se define una práctica de lectura singular en la que el lector debe ejercer un rol activo. Asimismo, nuestro estudio de casos, que abarca la obra completa de la escritora chicana, intentará mostrar que esta narrativa evidencia una búsqueda y una evolución respecto del empleo de estos elementos paratextuales que se manifiesta, entre otros aspectos, a partir de la elección de una lengua determinada. Como se recordará, hasta el momento Cisneros ha publicado tres obras narrativas: la novela de aprendizaje The House on Mango Street de 1984 (en adelante, Mango Street), la colección de relatos Woman Hollering Creek and Other Stories de 1991 (en adelante, WHC) y la novela Caramelo or Puro Cuento. A Novel, publicada en 2002 (en adelante, Caramelo).

En la sección siguiente presentaremos sucintamente algunas características de los epígrafes en tanto elementos paratextuales (Genette [1987] 2001) y sitios de la heterogeneidad interlingüe. En la tercera sección señalaremos algunas particularidades de los epígrafes en la narrativa de Cisneros, para luego dar cuenta a partir del análisis de un conjunto de epígrafes representativos de toda la obra de la escritora, por un lado, de la constitución discursiva de estos elementos de la paratextualidad que nos permiten ubicarlos en el terreno de la heterogeneidad interlingüe y, por otro, de la búsqueda discursivo-identitaria que manifiesta su escritura a lo largo de los años. En la última sección expondremos las contribuciones y los posibles temas de investigación que surgen como consecuencia de este trabajo.

\section{ACERCA DE LOS EPÍGRAFES COMO ELEMENTOS DE LA PARATEXTUALIDAD Y SITIOS DE LA HETEROGENEIDAD INTERLINGÜE}

Según Genette ([1987] 2001), el paratexto puede definirse como un espacio indefinido que rodea al texto, lo prolonga y le da presencia; se trata de un terreno indeciso que indica, incluso visualmente, los límites o fronteras del texto. En otras palabras, los elementos paratextuales se proponen como los umbrales del texto, sus puertas de entrada y de salida. Como veremos en el estudio de casos, los distintos elementos paratextuales de una obra determinada, que guardan, como propone Zoppi Fontana (2007), una estrecha relación entre sí, constituyen mecanismos de control discursivo y contribuyen, por tanto, a definir distintas instrucciones y prácticas de lectura.

En cuanto a los epígrafes, Genette indica que pueden entenderse como citas; situados en el borde mismo de la obra aparecen después de la dedicatoria y antes del texto, que podemos denominar aquí como principal. Respecto de sus funciones, entre las directas de los epígrafes se cuentan: esclarecer el título de la obra y comentar el

\footnotetext{
3 Emplearemos el término "latino/a" por sobre el término "hispano", en consonancia con la elección generalizada de las comunidades de Estados Unidos, que prefieren su uso, ya que este pone de relieve un vínculo entre sus comunidades y el resto de América Latina y los aleja de la denominación efectuada para clasificar a la población latina en los censos de Estados Unidos.
} 
texto en vistas de precisar su significación. Entre las funciones indirectas u oblicuas, se distingue la de otorgar, a través de su autor, una cierta garantía al relato que introducen. Finalmente, debemos considerar que la mera presencia del epígrafe produce un efecto de lectura sobre el que es preciso indagar.

Asimismo, siendo generalmente una cita, los epígrafes se constituyen en marcas de heterogeneidad en y para el texto. En tanto puntos de heterogeneidad (Authier 1984), los epígrafes rompen la unicidad aparente del hilo del discurso para presentar una voz otra, que también constituye al discurso desde fuera. En efecto, los epígrafes pueden entenderse como espacios discursivos que permiten la comunicación con un exterior, que resulta crucial para la constitución del discurso en vías de desarrollo.

Estos elementos pueden entenderse como formas de la autonimia simple (AuthierRevuz 1984, 1995); como se recordará, las formas de autonimia simple señalan un fragmento como extraño al discurso y conllevan la ruptura del orden sintáctico. En otras palabras, hay un fragmento puesto en mención en el discurso. Una de las formas más características de la autonimia simple es la cita directa, que constituye el modo de existencia más típico del epígrafe. En el caso del empleo de un epígrafe en obras literarias, se registra una cita directa sin presencia del marco citante, cuyo locutor -el autor de la cita- no coincide con el locutor responsable de la enunciación del texto, el narrador ${ }^{4}$. Así, la inclusión de un epígrafe implica la evocación de dos puntos de vista. Sabemos que en la articulación enunciativa de los planos que intervienen en toda cita se gesta un sentido discursivo particular; el epígrafe en el caso de la narrativa de Cisneros propone así un doble juego. A la conjunción de planos discursivos propia de toda cita se suma aquí una (doble) heterogeneidad interlingüe, la que se deriva de la puesta en escena simultánea de dos sistemas lingüísticos.

\section{El epígrafe en la obra de Sandra Cisneros}

La narrativa de Cisneros explora y explota distintos elementos de la paratextualidad, entre los que se destacan los epígrafes, que recorren toda su obra, y también las notas, que solo aparecen en su última novela. Según entendemos, en su obra la paratextualidad tiene dos cometidos principales. Por un lado, el paratexto tiende un puente intercultural que abrevia la distancia que hay con el otro, posiblemente representado también en la imagen de lector instituido en el texto. Por otra parte, los espacios enunciativos que se generan a partir de la dimensión paratextual se caracterizan exclusivamente por su condición fronteriza y heterogénea que se sustenta en la puesta en escena de dos sistemas lingüístico-culturales diferentes, dando paso

\footnotetext{
${ }^{4}$ Como sabemos, es posible realizar una analogía entre las categorías de locutor, originada en la polifonía enunciativa de Ducrot ([1984] 1986), y la categoría de narrador, que se inscribe en el marco de la narratología. Aun si no para ahondar en ello, el locutor (narrador), responsable de la enunciación de las novelas o de los cuentos, no debe equipararse al responsable de la enunciación global de la novela o de la colección de relatos. Esta figura, según entendemos, debe asemejarse a la de un locutor-Autor, categoría que hemos definido (Spoturno 2010), siguiendo los postulados de Ducrot ([1984] 1986) y de Eco ([1979] 1999), como una entidad discursivo-enunciativa que se constituye como origen de la obra literaria en su propio ámbito.
} 
así al interlingüismo que distingue la obra de esta escritora chicana ${ }^{5}$. Como queda dicho, a través de los epígrafes Cisneros señala la presencia efectiva o la alusión al español y/o al ámbito de la discursividad latina. En efecto, su narrativa manifiesta una búsqueda respecto del uso de este elemento que contribuye a delinear paulatinamente una práctica de lectura sobre la que volveremos más adelante.

Ahora bien, debemos notar que Mango Street no cuenta con un epígrafe de obra, de hecho, solo uno de los relatos que la componen, "Hips", aparece precedido por un breve epígrafe en inglés que recoge el fragmento de una canción infantil. Se advierte, sin embargo, que el empleo del epígrafe va adquiriendo su propio espacio y entidad conforme avanza en la narrativa. Así, en $W H C$, el epígrafe juega un rol más preponderante, pues aparece generalmente en español y registra fragmentos de canciones populares mexicanas, lo cual contribuye a la enunciación de este discurso que se plantea de manera explícita, al menos en los epígrafes, en un ámbito que se orienta al mundo latino. Si bien esta colección de relatos tampoco cuenta con un epígrafe de obra, cada una de sus secciones aparece introducida por un epígrafe en español que evoca el fragmento de alguna canción mexicana. En cuanto a los relatos, tres cuentan con epígrafes, dos en español, "Tin Tan Tan” y "Bien Pretty”, de las mismas características que los epígrafes de las secciones, y uno en inglés, que precede al cuento "One Holy Night" y se propone como un legado de la sabiduría maya.

En el caso de Caramelo, el espacio que se conforma a partir del uso del epígrafe es diferente, pues este se define en su vínculo con el interlingüismo de forma más explícita. La novela presenta nueve epígrafes que se distribuyen en el texto de la siguiente manera. Situado en el umbral, un epígrafe de obra que -emplazado en español y luego, en la página siguiente, en inglés- descubre el camino interpretativo que este elemento paratextual busca delimitar en tanto mecanismo de control discursivo. La primera sección de la novela, cuyo título es "Recuerdo de Acapulco", también cuenta con un epígrafe que, si bien está en español y recoge un trozo de una canción mexicana famosísima, "María bonita", de Agustín Lara, aparece seguido de una nota explicativa en inglés que instruye al lector respecto del contexto cultural-o exterior, en la terminología de Authier-Revuz $(1984,1995)-$, que se asocia a esta canción y al que este discurso apela en el proceso de su constitución. Por otro lado, hay dos epígrafes cuya existencia se da en español exclusivamente. Se trata de los Capítulos 37 y 52 de la novela; en ambos casos, los epígrafes son citas de dos canciones populares mexicanas: "La Zandunga" y "Cielito lindo" respectivamente. El primero de estos epígrafes contiene la marca explícita de su fuente en el texto, mientras que el segundo carece de ella, acaso porque el nombre del Capítulo 52 es justamente "Cielito lindo". Que estos dos epígrafes solo aparezcan en español responde, quizás, a que se trata en ambos casos de canciones mexicanas muy conocidas.

En cuanto a los cinco epígrafes restantes, hay tres que aparecen escritos en inglés fundamentalmente: el epígrafe del Capítulo 82 recoge la letra de una canción completa en inglés ("Think About Your Troubles") y los otros dos, que introducen el Capítulo 3 y la sección final de la novela titulada "Pilón", se hallan en inglés pero en su interior hay instancias de alternancia de lenguas de tipo emblemático (Poplack 1982); es decir, el español cumple la función de mostrar algún elemento cultural asociado a la otra

\footnotetext{
5 En efecto, estas características se reiteran en toda la obra de Cisneros, pero en el caso del paratexto se presentan, al parecer, como su razón de ser principal.
} 
lengua, pero no interviene en la enunciación del discurso en un nivel que sea distinto del léxico. Por último, hay dos epígrafes que acogen la letra de otras dos canciones mexicanas, que se presentan en versión bilingüe, o más exactamente, interlingüe, primero en español y, a texto enfrentado, en inglés. Se trata de las canciones "La Petenera" y "Júrame" que introducen los Capítulos 13 y 39 respectivamente. Al igual que en el epígrafe de obra, el español precede al inglés. De esta manera, aquí también se manifiesta una continuidad en el funcionamiento enunciativo-discursivo que refuerza las mismas instrucciones de lecturas que se evidencian en el primer epígrafe de la obra.

En líneas generales, en el empleo de los epígrafes de Caramelo es posible identificar todas las funciones del epígrafe señaladas por Genette a las que aludimos en la sección anterior. Desde la perspectiva de su funcionamiento enunciativo, los epígrafes que introducen los capítulos aparecen, por sus similitudes, vinculados entre sí en el ámbito de esta obra, lo cual contribuye a formar una malla intertextual dinámica a la que se incorporan también los títulos y las notas. Empleado de esta forma, el epígrafe indica al lector que la entrada a distintos pasajes de la novela se produce mediante la evocación de alguna pieza musical mexicana. Sin duda, esta constituye una fuerte instrucción de lectura. Asimismo, podemos afirmar que situar el relato desde el terreno de lo mexicano implica proponerlo como una suerte de garante discursivo para la enunciación que está en vías de producción.

\subsection{THE HOUSE ON MANGO STREET}

A continuación presentamos el análisis de algunos epígrafes seleccionado con el propósito de exponer una muestra representativa de su empleo a lo largo de la narrativa de Cisneros.

Tal como señalamos, Mango Street contiene solo un epígrafe, que introduce el relato titulado "Hips". Este epígrafe recoge tres de los versos de la canción infantil popular "Bluebells", la cual pertenece al ámbito de la discursividad anglosajona:

\section{I like coffee, I like tea}

I like the boys and the boys like me.

Yes, no, maybe so. Yes, no maybe so...

El texto principal del relato vuelve sobre esta rima infantil y sobre otras que contribuyen a estructurar el episodio que se organiza sobre la base del juego de saltar la cuerda. La acción de este relato y de toda la novela transcurre en un barrio latino de Chicago. Así, el exterior evocado en la alusión a estas canciones infantiles trae al discurso la voz colectiva de la comunidad, de aquello que es compartido por todos en una comunidad lingüístico-cultural determinada, en la que niños de origen latino saltan la cuerda al compás de una canción en inglés. La elección del inglés por sobre una canción infantil en español implica señalar la interrelación de dos mundos y muestra

\footnotetext{
${ }^{6}$ En la versión al español realizada por Elena Poniatowska, citada en la bibliografía de este trabajo, el cuento recibe el nombre de "Caderas" y el epígrafe es reemplazado por un fragmento de la rima infantil "Al pasar la barca", que pertenece a la discursividad latina y que orienta, por tanto, el discurso hacia otra dirección.
} 
la influencia de la escuela -probablemente aprendida en este espacio social-sobre el juego de los niños. Desde el borde del relato y a partir de este epígrafe particular, se construye una imagen discursiva del responsable de la enunciación que instruye aquí al lector respecto de la posible integración de estos dos mundos. En WHC, la enunciación procede de otra manera.

\subsection{WOMAN HOLLERING CREEK AND OTHER STORIES}

En esta obra, el epígrafe adquiere un rol mucho más protagónico que en Mango Street. De hecho, un epígrafe introduce cada una de las tres secciones que componen la colección. En cada una de estas secciones el epígrafe recoge dos versos de canciones populares mexicanas. El epígrafe de la primera sección aparece acompañado del seudónimo de su autor, Cri Crí, y de su nombre verdadero, Francisco Gabilondo Soler, pero no queda registrado el nombre de la canción. En efecto, se trata de un pequeño fragmento de una canción de este famoso compositor e intérprete mexicano titulada "La muñeca fea". Para el resto de las secciones, el texto señala también el nombre de la canción, del intérprete elegido y del autor. Pero examinemos en detalle el funcionamiento del primero de estos elementos paratextuales, que introduce la sección titulada "My Lucy Friend Who Smells Like Corn":

\section{También yo te quiero y te quiero feliz. \\ -CRI CRÍ}

(Francisco Gabilondo Soler)

En primer lugar se verifica una suerte de continuidad intertextual entre este elemento paratextual y el único epígrafe de Mango Street, que también recoge la cita de una canción infantil, pero en inglés. En este caso, el fragmento citado aparece en español, produciendo así una marca de heterogeneidad más fuerte para el discurso que en el caso anterior. En segundo término, con respecto al exterior que instaura este fragmento, la cita evoca una canción infantil mexicana muy popular que se destaca por la dulzura de su melodía y la ternura de la historia que cuenta. Este epígrafe resulta el vehículo ideal para que el lector ingrese en esta colección de relatos, ya que es la infancia de niños chicanos el tema central de la primera sección de WHC. Es preciso advertir prontamente que la alusión a la infancia se materializa a partir de la evocación de una canción que orienta el discurso explícitamente no solo hacia el ámbito latino, sino al terreno mexicano. De esta manera, el discurso exhibe la marca de su enunciación fronteriza desde el comienzo de la colección. Así, se distinguen dos fuertes instrucciones de lectura: por un lado se advierte una continuidad temática entre el epígrafe y las historias que este precede; por el otro, el español y la mención del origen de la cita obligan al lector a situar este discurso en el plano de otra discursividad y a comenzar a dialogar con ella, aun si no es posible comprender todo lo que tiene para decir. Y esta es una característica distintiva de WHC, cuya enunciación permite vislumbrar las huellas de su producción que, siendo visibles para todos los lectores, no son inteligibles en igual medida. A partir del espacio que configura este epígrafe, el responsable de la enunciación muestra y marca al otro que constituye la voz de su decir. 
Por último, la autoridad que le confiere un epígrafe al relato se ve aquí reforzada por el aval que otorga al texto el uso compartido que evoca la canción. La imagen discursiva (ethos) del responsable de la enunciación queda asociada así a la cosmovisión latina en general, y a la mexicana, en particular, dejando a un lado en la construcción de este espacio fronterizo el inglés y el mundo estadounidense, aun si esta es la lengua en la que se desarrollan fundamentalmente los relatos. Queda así establecida una instrucción de lectura central que atañe a la discursividad desde la que opera este discurso a través de la heterogeneidad interlingüe. En efecto, el español y los discursos que se le asocian constituyen las formas y marcas más explícitas de esta heterogeneidad.

Conforme avanzan los relatos, el epígrafe comienza a jugar un rol aún más importante y su condición de elemento marginal queda suspendida a causa de la relevancia y centralidad que adquiere para la construcción discursiva que se gesta en el interior mismo del texto. Para ilustrar su centralidad hemos seleccionado el epígrafe del cuento "Tin Tan Tan", ubicado en la última sección de WHC:

\section{Me abandonaste, mujer, porque soy muy pobre \\ $Y$ por tener la desgracia de ser casado. \\ Que voy hacer si yo soy el abandonado, \\ Abandonado sea por el amor de Dios.}

-"El Abandonado"

Al igual que en el ejemplo anterior, este epígrafe recoge un fragmento de una canción popular mexicana en español, en este caso, del compositor Miguel Aceves Mejía. En términos de la heterogeneidad interlingüe, debemos notar que el epígrafe aparece en español y que esta heterogeneidad queda señalada en el discurso explícitamente por el empleo de la letra bastardilla, que pone en evidencia con mayor fuerza la ruptura enunciativa que instaura el epígrafe en su condición de cita y forma, por ende, de la autonimia simple. La indicación de la fuente del discurso citado cierra el epígrafe, que en este caso solo indica el título de la canción de donde se extrajo el fragmento, "El Abandonado", escrito en letra redonda y sin indicación alguna respecto de su autor y/o intérprete, como ocurre en otros epígrafes ${ }^{7}$.

En tanto elemento que colabora a encauzar la interpretación de un discurso determinado, el epígrafe comporta siempre instrucciones de lectura. Este caso no es una excepción; sin embargo, las indicaciones que conlleva no están disponibles de la misma manera para todos los lectores. Si bien esta diferencia es una condición de la lectura, en la escritura de Cisneros, y particularmente en esta obra, se acentúa esta diferencia con gran vigor a partir de la instauración de la zona de frontera que su narrativa busca recrear y marcar. No hay en $W H C$ todavía, pues ya de ello se ocupará Caramelo, una voluntad de consensuar sentidos lingüístico-culturales con el lector. Es tiempo aquí de celebrar la frontera y de mostrar y marcar el origen, corriendo el riesgo de que los múltiples sentidos que pueden potencialmente activarse en el proceso de interpretación del discurso se desvanezcan.

\footnotetext{
${ }^{7}$ Este es el caso de los epígrafes de las secciones segunda y tercera, que aluden a las canciones "Piel Canela" y "Puñalada Trapera" y aparecen acompañados de los intérpretes elegidos y de los autores de las composiciones.
} 
Pero observemos ahora el funcionamiento discursivo de este epígrafe y los sentidos y discursos que le están asociados. Como hemos señalado, los elementos paratextuales de una obra se hallan en relación de intertextualidad. En este caso, el epígrafe se vincula con el título del relato que precede, es aludido en el texto, reaparece en el cuento siguiente, "Bien Pretty", y ya estaba presente cinco cuentos antes, en "Eyes of Zapata". Recordemos rápidamente el argumento de este brevísimo relato para poder así comprender mejor la trama intertextual que se teje desde el borde hacia el centro y viceversa a lo largo de esta colección. Desde la perspectiva de Rogelio Velasco, "Tin Tan Tan" refiere el final de una historia de amor entre este personaje y una mujer. Rogelio cuenta su pena de amor causada por el abandono de su amada, sin presentar una razón válida para el abandono. Esta razón se halla justamente en el epígrafe, que propone una clave de lectura para abordar el texto, sin la cual no es posible comprender el conflicto que plantea esta historia de amor. Es interesante, entonces, ponderar algunas de las situaciones de lectura posibles. Quien sabe español puede recuperar las razones que causaron el abandono de la mujer, ya que estas se encuentran inscriptas en el fragmento de la canción citado, que sanciona la pobreza, único motivo de abandono aludido en el cuento. Sin embargo, las razones de este abandono se vinculan con la condición civil del personaje masculino, motivo real de la ruptura, como dice el epígrafe del relato y como luego es posible apreciar en el cuento "Bien Pretty", que continúa la línea argumental, presentando la historia desde el punto de vista de la mujer, Guadalupe Arredondo o Lupita. El lector anglohablante queda aquí a medio camino, ya que en este caso no se propone ninguna traducción. Esto ocurre en otros pasajes de la colección donde la escritura deja ver ese otro que sustenta el discurso y que, aun si no puede ser comprendido por todos los lectores, es mostrado y marcado. Así, se configuran un gesto de lectura determinado y una imagen para el responsable de la enunciación, que se exhibe en la toma de todas estas decisiones que conciernen a la enunciación fronteriza de su discurso.

Y si bien es cierto que el lector anglohablante queda en esta zona de frontera, también debemos notar que el lector avezado, cuyo bagaje lingüístico-cultural le permite reconocer el mundo latino que este epígrafe trae al discurso, encontrará la manera de descifrar los acertijos textuales que se entretejen en derredor de este epígrafe. La escritora ha dejado pistas en otros relatos que permiten relacionar este cuento, a partir del epígrafe, con otros dos de la colección: "Bien Pretty" y "Eyes of Zapata". En este último, Cisneros recrea un episodio muy importante de la historia mexicana a través de una historia de amor imaginaria entre Inés Alfaro y el general Emiliano Zapata, uno de los líderes de la Revolución Mexicana (1910-1917). La narradora de este relato, Inés Alfaro, mantiene un diálogo imaginario con Zapata, en el que le dice: "You used to be tan chistoso. Muy bonachón, muy bromista. Joking and singing offkey when you had your little drinks. Tres vicios tengo y los tengo muy arraigados; de ser borracho, jugador, y enamorado..." (Cisneros 1991: 89). Así, la alusión a la canción "El Abandonado", que caracteriza en "Tin Tan Tan" la conducta de un hombre mexicano en su relación con una mujer chicana, también aparece mencionada en el cuento "Eyes of Zapata", en español y señalada por la letra bastardilla, para describir nuevamente la naturaleza de la conducta de un hombre mexicano para con su amante. Y aquello que aparece mencionado explícitamente en el epígrafe de "Tin Tan Tan" -se trata de un hombre pobre y casado- no surge en el fragmento de la canción que aparece en este relato, en el que la condición civil de Zapata -el general mexicano 
está casado con otra mujer- juega también un rol importante para su amante. Aquí, la voz de Inés Alfaro sí deja en claro que se trata de una canción a través de la manera en que introduce la cita en el texto: "Joking and singing off-key when you had your little drinks". Así, la relación que se establece entre los dos textos contribuye a definir un gesto interpretativo determinado en el que la discursividad mexicana, a partir de la alusión a una canción, plantea las claves para la caracterización de los personajes masculinos y para dar sentido completo a la trama de los relatos.

Volviendo al relato "Tin Tan Tan", debemos advertir que el epígrafe también da una indicación respecto de la lectura del título, elemento paratextual que también ofrece instrucciones de lectura muy precisas que solo son comprensibles en su vínculo con el epígrafe. En el título se esconde el pseudónimo de uno de los más grandes actores, comediantes y cantantes mexicanos, pues Tin Tan era el nombre artístico de Germán Gómez Valdés Castillo (1915-1973). También apodado "el Pachuco de Oro", Tin Tan pasó a la historia por sus célebres interpretaciones de distintas canciones populares mexicanas, por su actuación en el cine nacional mexicano y por representar y dignificar en sus películas la imagen del pachuco, que constituye un ícono para la identidad chicana $^{8}$. A la luz de este nuevo discurso evocado, el vínculo entre el epígrafe y el título se resignifica, pues Tin Tan fue uno de los intérpretes de "El Abandonado" y el título, cuyo sentido quedaba tal vez librado al azar, se encauza para señalar una huella interpretativa que posiciona la marginalidad en el mismo centro de la escritura. Se evidencia en esta operación y en esta elección una indicación ideológica. No se trata simplemente de un buen actor o intérprete, sino de aquel artista cuyo nombre se asocia a la reivindicación del chicano en la frontera. Y hay otro eco de esta asociación en los pasajes de este relato, que se manifiesta a través de la marca que instaura la traducción literal al inglés del siguiente enunciado paremiológico: "They say of the poet and madman we all have a little”. En efecto, además de los discursos que se activan al emplear la voz proverbial, en este caso debemos advertir la evocación de otro discurso, pues "Músico, poeta y loco" es una película mexicana en la que Tin Tan registra su actuación más reconocida al interpretar la canción "Bonita" de Luis Arcaraz, acaso una anticipación para el título del cuento posterior, "Bien Pretty" vez más, que el sentido es discursivo y que se halla en las alusiones que se asocian a las entidades lingüísticas. Es precisamente esa evocación de múltiples sentidos la que permite dar cuenta de la heterogeneidad interlingüe e intercultural que halla su espacio propio en la frontera que celebra la escritura de Cisneros.

\subsection{CARAMELO OR PURO CUENTO. A NOVEL}

Según señalamos en la primera parte de esta sección, la novela Caramelo presenta tres tipos de epígrafes diferentes. Hay epígrafes escritos en español, epígrafes escritos

\footnotetext{
${ }^{8}$ Los pachucos, como señala Paz ([1950] 2004), son grupos de jóvenes, cuyo origen es generalmente mexicano y se remonta a la década de los años veinte. Se trata de una tribu urbana que se caracteriza por tener una vestimenta, lenguaje y conducta singulares. Paz tiene una visión polémica del pachuco que ha suscitado fuertes críticas. Para ampliar, se podrá consultar Arteaga (1997) y cotejar el poema "Pachuco Paz" de Alurista. Por otro lado, debemos agregar que la interpretación de Tin Tan del pachuco hizo que muchos otros se identificaran con el modo de vestir y actuar propios de los pachucos, aun si no pertenecían a este grupo.

${ }^{9}$ El subrayado es nuestro.
} 
en inglés, generalmente con una presencia marcada del español ${ }^{10}$, y epígrafes que aparecen en versión bilingüe, vinculados por la traducción. En la mayoría de los casos de Caramelo, al igual que en $W H C$, los epígrafes recogen fragmentos de canciones populares mexicanas en español, razón por la que su funcionamiento enunciativodiscursivo guarda similitud con la descripción realizada para los epígrafes de $W H C$; al igual que en esa obra, los epígrafes de Caramelo colaboran a orientar la discursividad hacia el ámbito del mundo latino y, más específicamente, del mundo chicano que evoca permanentemente su origen cultural mexicano. Pero aquí debemos considerar una gran diferencia entre uno y otro empleo del epígrafe. En Caramelo, los epígrafes que citan pasajes de canciones en español no llevan nunca la huella de la letra bastardilla. Como se recordará, en el caso de $W H C$, el español -lengua en la que están escritos prácticamente todos los epígrafes- aparece siempre señalado por la letra bastardilla, lo cual instaura una marca explícita de heterogeneidad en relación con el fragmento puesto en mención en la cita que constituye el epígrafe. Y es importante destacar este cambio concerniente a los aspectos gráficos, porque en los epígrafes de esta novela el otro aparece pero solo es mostrado, no marcado. Se trata de una característica central de la heterogeneidad interlingüe que se evidencia principalmente en la última novela de la escritora chicana.

Sin duda, el empleo de citas extensas en los epígrafes, como las de Caramelo, constituye una instancia fuerte de heterogeneidad, por cuanto ese otro que ingresa al discurso en la articulación de la cita hace sentir su presencia de manera contundente. Pero, como anticipamos, la presencia de ese otro no siempre conlleve un rasgo que lo haga aparecer como un discurso otro, reviste gran significación. Por un lado, al estar escritas sin resalte tipográfico, las citas de canciones en español aparecen integradas al hilo del discurso en mayor medida. El empleo de la letra bastardilla, la negrita o las comillas señala un punto de heterogeneidad explícito para el discurso. En cambio, el hecho de no señalar el español como un "cuerpo extraño" para el discurso en vías de enunciación indica una clara posición respecto de la consideración de su estatus dentro de una obra escrita fundamentalmente en inglés y que tiende a igualar sistemas haciéndolos participar de una misma enunciación sin marcar su naturaleza diferente. Por otra parte, este rasgo se constituye en una instrucción de lectura para el lector, que debe ahora comenzar a ver la lengua española como parte constitutiva de la escritura de la novela. Por medio de este tipo de estrategias, el responsable de la enunciación que podemos identificar con la entidad ficticia del Autor le otorga al español un lugar que se construye como propio, acaso como ganado, dentro de la enunciación. Así, en Caramelo se mantiene el uso estratégico del epígrafe, pero el discurso reconoce más abiertamente el interlingüismo como sitio de su enunciación.

Asimismo, es posible realizar otras consideraciones respecto de los epígrafes que aluden a trozos de canciones populares mexicanas en español en esta novela. En primer lugar, se evidencia una fuerte instrucción que ya no atañe simplemente a la lectura del texto, sino a otros aspectos que se ubican, gracias al paratexto, en derredor del texto. En la obra de Cisneros, el epígrafe evoca el sonido y la textura de la música mexicana para instalarlos ya desde el comienzo del texto al que ingresamos oyendo la voz de Agustín Lara interpretando "María Bonita", su composición más

${ }^{10}$ La única excepción a esta caracterización la constituye el epígrafe del Capítulo 82, que recoge, como ya hemos señalado, la letra de la canción "Think About Your Troubles". 
célebre. De esta manera, se le recuerda al lector que no solo debe leer a su paso por esta narrativa, sino escuchar. Se trata, especialmente en Caramelo, de la lectura que se hace con la ambientación que genera la música. En segundo lugar, este uso sistemático del epígrafe contribuye también a recuperar una escena de la historia artística de México, que se corresponde cronológicamente con los tiempos del padre de la escritora, Alfredo Cisneros del Moral, a cuya época busca rendir tributo esta novela. Por otra parte, observamos de nuevo que se tejen relaciones de intertextualidad entre los distintos elementos del paratexto y que las instrucciones de lectura que aparecen en la dedicatoria de Para ti, Papá, se continúan y refuerzan en los sentidos aludidos en los epígrafes.

Situándonos en el espacio específico de algunos de los epígrafes de Caramelo, notamos que esta es la única de las obras narrativas de Cisneros que cuenta con un epígrafe de obra:

\section{Cuéntame algo, aunque sea una mentira.}

Tell me a story, even if it's a lie.

Según se aprecia, la cita de este epígrafe se presenta en dos versiones, que aparecen en dos hojas diferentes: primero en español, y luego en inglés. Se trata de una operación enunciativa que funciona en dos sentidos: por un lado, continúa las indicaciones del título, que aparece en español principalmente, Caramelo or Puro Cuento, pero cuyo subtítulo corresponde al inglés, A Novel; por el otro, esta operación deja, al menos, en suspenso las indicaciones de la dedicatoria que aparece solo en español. Por otra parte, debemos observar que la versión en español aparece, al igual que en el caso de la dedicatoria, nuevamente señalada por la letra bastardilla, instaurando así una marca de heterogeneidad doble ${ }^{11}$. En este punto, el epígrafe de obra difiere de los epígrafes que citan canciones y aparecen en español. Asimismo, el orden en el que aparecen estas dos versiones del epígrafe también instruye al lector respecto del hecho de que la lengua que señala el origen en esta narrativa es el español y la que marca el destino, o la meta, es el inglés. En otras palabras, este ordenamiento, que es convencional en la presentación bilingüe de un texto traducido, pone sobre aviso al lector respecto de una de las operaciones discursivas que Cisneros orquesta en su escritura y que se vincula íntimamente con la traducción.

Con respecto a las funciones conceptualizadas por Genette, podemos decir que el epígrafe retoma el sentido del título, lo esclarece y lo resignifica. Atribuir la responsabilidad de este enunciado no resulta tarea sencilla: ¿cuál es la voz que ingresa al relato a través del epígrafe? Este epígrafe no evoca la palabra de otro autor o sujeto de enunciación explícitamente. En el universo de la novela podrían identificarse los rasgos discursivos del responsable de la enunciación con las características de la narradora principal y de la narradora secundaria, es decir, con Celaya y con su abuela Soledad, que es quien encomienda la historia a su nieta desde la tumba y en ocasiones toma la palabra. La mentira a la que alude el epígrafe impone una vuelta al título para aquellos lectores capaces de comprender el sentido de "puro cuento". Se establece una relación de intertextualidad entre estos dos elementos paratextuales. Debemos notar que a medida que avanza la historia, el objeto del relato evocado en el epígrafe

11 Debemos aclarar que en esta narrativa el empleo del español no aparece marcado por la letra bastardilla sistemáticamente, por lo que su presencia o ausencia reviste significación. 
termina siendo la historia misma, que puede condensarse en la frase "caramelo, o puro cuento". Se aprecia también la función anticipatoria de este elemento paratextual. A lo largo de la novela habrá súplicas por parte de Celaya y de la abuela para que la historia continúe, para que la historia, simbolizada por medio de un rebozo inconcluso de color caramelo, pueda encontrar su final y la abuela logre, a través de su nieta, contar su verdad, obtener el perdón de aquellos a los que hirió y descansar en paz.

Asimismo, debemos señalar otra relación de intertextualidad que el epígrafe mantiene con otro texto y que aparece explicitada en la sección de Agradecimientos de permisos de autor al final de la obra. La oración que compone el epígrafe -"Cuéntame algo, aunque sea una mentira"- está extractada de Translated Woman. Crossing the Border with Esperanza, de la antropóloga cubano-estadounidense Behar ${ }^{12}$. El epígrafe, y, por su intermedio, la obra, establece una suerte de diálogo con un texto que lo precede en el tiempo y también con otro que lo sucede, que tienen como característica común ser parte de la producción de dos escritoras latinas que escriben en inglés en Estados Unidos, entre otras cuestiones, sobre la experiencia de la inmigración latina a ese país ${ }^{13}$.

Ya inmersos en la trama de la novela, el epígrafe reconoce una nueva función que mencionamos al anticipar las características de estos elementos paratextuales en Caramelo. Los epígrafes correspondientes al Capítulo 13, "Niños y Borrachos", y al Capítulo 39, "Tanta Miseria"14, extractan dos canciones populares mexicanas en español -el dominio popular de origen oaxaqueño llamado "La Petenera" y la canción "Júrame" de la compositora mexicana María Grever respectivamente-, que aparecen seguidas de una versión en inglés. A continuación presentamos el epígrafe que encabeza el Capítulo 39:

$$
\begin{array}{r}
\text { Ciuame } \\
\text { Todos dicen que es mentira que } \\
\text { te quiero } \\
\text { porque nunca me habían visto } \\
\text { enamorado, } \\
\text { yo te juro que yo mismo } \\
\text { no comprendo } \\
\text { el por qué tu mirar me } \\
\text { ha fascinado. } \\
\text { Cuando estoy cerca de ti } \\
\text { y estás contenta } \\
\text { no quisiera que de nadie } \\
\text { te acordaras, } \\
\text { tengo celos hasta del } \\
\text { pensamiento } \\
\text { que pueda recordarte a otra } \\
\text { persona amada. }
\end{array}
$$

Qromise Me

Everyone says it's a lie

I love you because no one's seen me in love,

I swear I don't understand

why your gaze has me so fascinated.

When I'm close to you and you're happy I don't want you thinking of anyone else,

I'm even jealous of your thoughts that might remind you of another.

\footnotetext{
12 Esta oración aparece en la obra de Behar (1993) en la pág. 18.

13 En 2009, Ruth Behar publicó un libro que se titula: Tell me something, even if it is a lie/ Cuéntame algo, aunque sea una mentira: Las Historias de la Comadre Esperanza/ Stories of Godmother Esperanza.

14 Se trata de los títulos de los capítulos de la novela original, no de su traducción. Se advertirá el uso de la mayúscula inicial para todas las palabras plenas, que corresponde a una convención del inglés.
} 
Júrame, que aunque pase mucho tiempo no olvidarás el momento en que yo te conocí, mírame, pues no hay nada más profundo ni más grande en este mundo, que el cariño que te di. Bésame, con un beso enamorado, como nadie me ha besado desde el día en que nací. Quiéreme, quiéreme hasta la locura, y así sabrás la amargura que estoy sufriendo por ti.
Promise me though time passes you won't forget the moment we met, look at me, there's nothing deeper nor greater in this world than the love I give you.

Kiss me with a lover's kiss, like no one's kissed me since the day I was born. Love me, love me till madness, and that's how you'll know the bitterness I'm suffering for you. -composer, María Grever

To be accompanied by the scratchy 1927 version of "Júrame," as recorded by José Mojica, the Mexican Valentino, who would later renounce fame, fortune, and the adulation of millions of female fans by taking vows and becoming a priest.

His life makes a wonderful story and was adapted into that unforgettable film... What was its name again?

If you've never heard Mojica, imagine a voice like Caruso, a voice like purple velvet with gold satin tassels, a voice like a bullfighter's bloody jacket, a voice like a water-stained pillow bought at the Lagunilla flea market embroidered with "No Me Olvides," smelling of chamomile, copal, and cat.

Como se puede apreciar, no es el carácter bilingüe o interlingüe del epígrafe el único rasgo novedoso que acompaña este elemento paratextual. La indicación de la fuente que sigue a la cita no solo señala el nombre de la autora de la composición, sino que comporta también otras instrucciones de lectura. Estas, que se materializan en regiones diferentes de la textualidad, aparecen aquí reunidas en un mismo espacio textual que corresponde sensu stricto al ámbito del paratexto.

Las dos particularidades específicas de este largo epígrafe so, en primer lugar, la inclusión de una canción casi completa y de su traducción que acarrea, sin duda, una nueva instrucción para el lector de esta obra. Expuesto primero en español y luego en inglés, este epígrafe continúa la indicación conferida en el epígrafe de la obra, que también se presenta en versión bilingüe o interlingüe al lector, señalando ciertas claves que atañen a la traducción, que se constituye en un rasgo distintivo de esta narrativa y en una operación medular para la heterogeneidad interlingüe. En relación con esta operación de traducción, es preciso hacer una distinción respecto del estatus diferente de la canción en español y de su versión en inglés. No se trata de una canción que a partir de la traducción tenga presencia en el ámbito de la discursividad anglosajona. Por esta razón, su estatus no puede equipararse al de canciones como "My Way" o "Sólo Tú", que, aun siendo traducciones ${ }^{15}$, cobran vida propia en otras

15 Como se recordará, "My Way" y "Sólo Tú" son versiones de las canciones "Comme D'Habitude" de Gilles Thibault y "Only You (And You Alone)" de Buck Ram y Ande Rand respectivamente. 
discursividades que las acogen en su interior. Resulta evidente que este no es el caso de las canciones de los epígrafes bilingües, cuya existencia en inglés depende de la interrelación explícita que se establece en el texto. En segundo término, es preciso notar que el español de este epígrafe, como anticipamos al comienzo de esta sección, no aparece señalado como un cuerpo extraño por medio de la letra bastardilla, ni en la versión en español, ni en la versión en inglés. Así, se corrobora nuestra hipótesis de que en esta última novela la enunciación se orienta al diálogo y a la negociación de sentidos lingüísticos y culturales en mayor medida que en las obras anteriores de la escritora chicana ${ }^{16}$.

En cuanto a su relación con el texto que introduce, el epígrafe colabora a anticipar el tema del capítulo en el que la trama del relato se mueve hacia la historia de celos y engaño que ha sufrido Soledad Reyes, la abuela de la narradora. Ahora bien, debemos notar que la reelaboración del paratexto (texto de la canción) en el texto (cuerpo del capítulo) no se produce generalmente con los mismos términos que registra la traducción en el epígrafe: "-Júrame. Swear, swear to me it's only me you love, my life, júrame./Te lo juro. I swear." (Cisneros 2002: 184). Distintas conclusiones pueden desprenderse de esta nueva cita. Por un lado, el texto principal del capítulo retoma la invocación de la canción, "júrame", pero no la traducción propuesta, "promise me", que resulta un equivalente dinámico-funcional y cultural más ajustado. La literalidad de la versión ofrecida en el cuerpo del capítulo caracteriza el habla del personaje de la abuela que debe traducirse al inglés en su discurrir, pero también ilustra una voluntad por mostrar extrañeza en el empleo de esa forma resultante que aparece a partir de la traducción del español aludida y que deja el inglés subordinado al español. De esta operación dan cuenta tres elecciones diferentes: el verbo "swear" en lugar de "promise", el complemento de objeto indirecto que lo acompaña, "to me", que no se corresponde con el paradigma de este verbo en inglés, y la forma de vocativo "my life", que constituye una traducción palabra por palabra del vocativo "mi vida" del español. Por otra parte, es preciso notar que aquí el español aparece marcado como una alteridad por medio de la letra bastardilla, trayendo al discurso más fuertemente una escena enunciativa diferente, que se nutre directamente del español y de las asociaciones que se construyen alrededor de esa lengua.

Asimismo, deseamos llamar la atención sobre la articulación de este epígrafe. A su cuerpo principal compuesto por las dos versiones de la canción "Júrame", le sigue una serie de indicaciones que contribuyen a acrecentar su complejidad enunciativa. En una tipografía de resalte, la mención de la compositora de la canción y tres párrafos sucesivos dan cierre a este extenso epígrafe. Desde un punto de vista enunciativo, las voces que surgen en estos párrafos no coinciden con la voz que aparece en la canción; se trata, pues, de voces distintas, incluso dentro de los mismos párrafos, en los que este hecho se señala a partir de una tipografía diferente. La voz que se evidencia en el segundo párrafo, escrito en negrita, coincide con los rasgos de uno de los personajes de la historia. Es la abuela Soledad quien retoma aquí el discurso

\footnotetext{
16 Por otro lado, debemos tener presente que en el Capítulo 13 "Niños y Borrachos" aparece ya una alusión directa a la canción de María Grever. Curiosamente, este es el otro capítulo que contiene un epígrafe en dos lenguas. A continuación, transcribimos el fragmento: “-No, the Grandmother announces matter-of-factly. -She can't sing. Juchi, play that song I like, the one from my times, 'Júrame.'" Come on, don't be bad, play it for me. Todos dicen que es mentira que te quiero..." (Cisneros 2002: 59). Como se advertirá, el título de la canción está escrito sin ningún resalte tipográfico, pues las comillas responden a una convención.
} 
con una intervención de ultratumba. Pero hay otra voz que busca orientar el discurso desde la marginalidad de este elemento paratextual. Mediante un discurso explícitamente instructivo ("to be accompanied", forma impersonal del imperativo pasivo), esta voz le señala al lector qué versión de la canción de Grever debe escuchar, pues aunque ha tenido muchas interpretaciones y muy buenas, es la versión del mexicano José Mojica la que el discurso señala como clave en el proceso de su constitución. Por medio de esta mención se entreteje en este espacio paratextual otra narrativa que alude a personajes de la vida real por medio de la evocación de la compositora María Grever (1894-1951), del reconocido intérprete José Mojica (1895-1974) y de un hecho que los une, pues la Grever saltó a la fama cuando en 1926 Mojica aceptó cantar su opera prima "Júrame". Por otra parte, la instrucción de lectura aludida da cuenta de una voluntad por dominar el sentido discursivo que comienza en el umbral del texto y que luego se reforzará de distintas maneras, también a la postre, como se verifica en los diversos tipos de notas de la novela.

Por otra parte, se advierte que el decir de esta voz sufre la interrupción de la abuela, otro locutor o narrador secundario, que se entromete incluso en el paratexto de la historia en el deseo de orientar y dominar el sentido a través de una pregunta que alude a la película que se filmó en torno a la vida de Mojica. En esta puja por la palabra y el sentido, no queda del todo claro quiénes son los contrincantes. Se podría pensar que se trata de la figura de la narradora principal de la historia, Celaya; sin embargo, esta voz adopta en el epígrafe una perspectiva distinta respecto de la historia y de la interrupción de la abuela, conducta que dentro del texto hubiera tenido otra reacción por parte de su nieta, como ocurre por ejemplo en el Capítulo 22 de la novela ${ }^{17}$. El lector retoma el último párrafo del epígrafe en busca de una respuesta a la pregunta de la abuela, pero su voz aquí es desoída y el lector deberá encontrar la respuesta al interrogante planteado en otro sitio, más por fuera del texto todavía. Se trata de la película "Yo pecador", del director Alfonso Corona Blake, que se basa en la autobiografía de Mojica, quien, como también indica el epígrafe, decidió abandonar la fama y la vida mundana para dedicarse a su fe, razón por la que se ordenó como sacerdote. Pero hay algo que esta voz sí nos indica en el último párrafo respecto del tono, la textura, el color, el tiempo, el sabor y el aroma de la voz de José Mojica, pues no puede pasar inadvertido que el aroma que impregna esa voz es el de la manzanilla, pero, más importante aún, el del copal, palabra que aparece en español y señalada por una tipografía especial que la distingue del resto del texto y que alude a una costumbre ancestral de los antiguos mexicanos. Esta es, en efecto, otra forma de vida del español en la escritura de Cisneros, que se evidencia también en el seno de $W H C$.

\footnotetext{
17 It was never rosy, and it certainly wasn't charming. It was smelly, dank, noisy, hot, and filled with vermin.

Who's telling this story, you or me?

You.

Well, then.

Go on, go on. (Cisneros 2002: 97).
} 


\section{A MODO DE CONCLUSIÓN}

Hemos indagado acerca de la construcción y del funcionamiento enunciativodiscursivo de los epígrafes en la obra narrativa completa de la escritora chicana Sandra Cisneros. Nuestro estudio de casos, centrado en el estudio de la heterogeneidad interlingüe, da cuenta del contacto lingüístico-cultural que se produce en el ámbito de una de las fronteras claves del texto a partir del encuentro del inglés y del español. Los epígrafes en esta narrativa constituyen espacios enunciativos intersticiales que permiten la comunicación entre distintas discursividades y que muestran y marcan al otro al que este discurso recurre en el proceso de su constitución. Pero la estrategia de señalar y marcar al otro, repetida y explorada a través de los epígrafes de distintas maneras, implica un replanteamiento del sentido supuestamente secundario de la paratextualidad, pues el margen termina por adquirir gran centralidad en la escritura de Cisneros. Ningún estudio que sea de nuestro conocimiento había abordado de manera sistemática este aspecto de la paratextualidad en la obra de la escritora chicana.

Hemos verificado que la enunciación de este discurso reconoce espacios distintivos que se plasman en la paratextualidad. Más específicamente, hemos puesto el énfasis en la descripción de las zonas textuales que se gestan en torno a los epígrafes, la cual, según entendemos, contribuye significativamente al esclarecimiento del funcionamiento enunciativo-discursivo de esta escritura. El análisis de una muestra representativa de los epígrafes de la obra de Cisneros señala que estos elementos, que aparecen en español o asociados a esa lengua, instauran marcas que deben entenderse como sitios de la heterogeneidad interlingüe constitutiva de este discurso. Asimismo, el examen de todos los epígrafes da cuenta de una búsqueda discursivo-identitaria de la escritora que se manifiesta en la experimentación progresiva que Cisneros se propone con las lenguas que confluyen en su discurso, principalmente el español y el inglés. Los ejemplos analizados manifiestan la presencia cada vez más ostensible del español y de los discursos que se le asocian.

Es posible concluir que estos elementos funcionan como umbrales que permiten al lector ingresar a través de la obra literaria en un universo lingüístico-cultural que evoca la cosmovisión latina de manera constante. De este modo, se define también una imagen discursiva (ethos) del responsable de la enunciación global que reconoce distintas filiaciones con respecto a los sistemas lingüístico-culturales que hace intervenir en su decir. El empleo efectivo o la alusión al español en un texto que está fundamentalmente escrito en inglés se vuelve una marca de identidad, un recurso clave para la constitución de este discurso, que se inicia en el paratexto, el cual, según afirma Genette ([1987] 2001) citando a Borges, es un vestíbulo del texto. Y, en tanto vestíbulo, el paratexto en la obra de Cisneros se vuelve un espacio de recibimiento para el lector, que se erige sobre los cimientos de dos sistemas lingüístico-culturales diferentes y que anticipa de esta manera los materiales de construcción de que está hecho el resto de la obra. Según hemos visto, la voluntad por definir y encauzar el sentido del discurso a través de las distintas instrucciones de lectura que confieren los epígrafes se hace más evidente en la última novela de Cisneros, la cual también abunda en notas que contienen prolongaciones de la ficción, datos histórico-culturales y comentarios metadiscursivos que se orientan en este mismo sentido. 


\section{Obras CITADAS}

\subsection{PRIMARIAS}

Cisneros, Sandra. [1984] 1991. The House on Mango Street. Nueva York: Vintage Contemporaries.

-_. 1991. Woman Hollering Creek and Other Stories. Nueva York: Vintage Contemporaries.

—_. 1994. La casa en Mango Street. Trad. Elena Poniatowska. Nueva York: Vintage Español.

—. 2002. Caramelo or Puro Cuento. A Novel. Nueva York: Vintage Contemporaries.

\subsection{SECUNDARIAS}

Amossy, Ruth, ed. 1999. Images de soi dans le discours. La construction de l'ethos. Lausana: Delachaux et Niestlé.

Arteaga, Alfred. 1997. Chicano Poetics. Heterotexts and Hybridities. Australia, EE.UU. y Reino Unido: Cambridge University Press.

Authier-Revuz, Jacqueline. 1984. "Hétérogénéité(s) énonciative(s)". Langages 73: 98-111.

- 1995. Ces mots qui ne vont pas de soi. Boucles réflexives et non-coüncidences du dire. París: Larousse.

Bajtin, Mijail. [1952-3] 1982. Estética de la creación verbal. México D.F.: Siglo XXI Editores.

Behar, Ruth. 1993. Translated Woman. Crossing the Border with Esperanza's Story. Boston: Beacon Press.

Cantero, Mónica y Polly Stewart. 2003. "La creación del español mestizo en la literatura chicana: identidad y elección lingüística”. Actas del XIII Congreso Internacional de español como lengua extranjera. <www.sgci.me.es/redele/biblioteca/asele/16.cantero_stewart. pdf> [consulta: 28-9-2006].

Cintron, Zaida y Eva Mendieta-Lombardo. 1995. "Marked and Unmarked Choices of Codeswitching in Bilingual Poetry". Hispania 78: 565-572.

Ducrot, Oswald. [1984] 1986. El decir y lo dicho: Polifonía de la enunciación. Barcelona: Paidós.

Eco, Umberto. [1979] 1999. Lector in fabula. La cooperación interpretativa en el texto narrativo. Trad. Ricardo Pochtar. España: Editorial Lumen, $4^{\mathrm{a}}$ edición.

García Negroni, María Marta. 2000. “Acerca de los fenómenos de relectura y reinterpretación en el discurso". Discurso y Sociedad 2.4: 89-108.

Genette, Gérard. [1987] 2001. Umbrales. Trad. Susana Lage México D.F.: Siglo XXI Editores.

Ledwith, Lorrain. 2008. "A Linguistic and Sociolinguistic Analysis of Code Switching in Sandra Cisneros' Caramelo”. Universidad de Nottingham. Tesis de maestría.

Lipski, John. 1982. "Spanish-English Language Switching in Speech and Literature: Theories and Models". The Bilingual Review/La Revista Bilingüe 9: 191-212.

Maingueneau, Dominique. [1986] 1993. Élements de linguistique pour le texte littéraire. París: Dunod, $3^{\mathrm{a}}$ ed.

—. 1999. "Ethos, scénographie, incorporation". Images de soi dans le discours. La construction de l'ethos. Ed. Ruth Amossy. Lausana: Delachaux et Niestlé. 75-102.

Paz, Octavio. [1950] 2004. El laberinto de la soledad. México D.F.: Fondo de Cultura Económica. 
Poplack, Shana. 1982. "Sometimes I'll start a sentence in Spanish y termino en español: toward a typology of code-switching". Spanish in the United States. Sociolinguistic Aspects. Eds. John Amastae y Lucía Elías Olivares. Cambridge: Cambridge University Press. 230-263.

Rudin, Ernst. 1996. Tender Accents of Sound. Spanish in the Chicano Novel in English. Tempe: Bilingual Press/Editorial Bilingüe.

Soler-Espiauba, Dolores. 2001. "Mestizaje lingüístico: funciones del español y del inglés en la expresión de los sentimientos en la narrativa hispana femenina de EE.UU." Estudios de lingüística española. Ed. Bob de Jonge. <http://elies.rediris.es/elies13/soler.htm> [consulta: 10-10-2006].

Spoturno, María Laura. 2010. Un elixir de la palabra. Heterogeneidad interlingüe en la narrativa de Sandra Cisneros. Universidad Nacional de La Plata, Argentina. Tesis doctoral.

Zoppi Fontana, Mónica. 2007. "En las márgenes del texto, intervalos de sentidos en movimiento". Páginas de Guarda I, 4: 11-39. 
